\title{
Impact of implementing controlling on enterprise employees
}

\author{
Jarmila Klementová ${ }^{1, *}$, Zuzana Stroková ${ }^{1}$ \\ ${ }^{1}$ Technical University in Zvolen, Faculty of Wood Sciences and Technology, Department of \\ Economics, Business and Management, T.G. Masaryka 24, 96001 Zvolen, Slovak Republic
}

\begin{abstract}
Implementing controlling into business practice is a difficult, long-term and complex process that is unique for each enterprise. It is affected by various psychological factors that evoked positive and negative emotions in owners, managers and employees. The main objective of this paper is to identify key psychological factors, emotions and barriers affecting employees during implementing controlling into business practice. The empirical research into the given problem was conducted by the questioning method in a form of questionnaire. In order to evaluate the research results, the descriptive, graphical, and mathematic-statistical methods were used. Based of the findings, a concept was proposed to put emphasis on the key psychological aspects of the enterprise employees during implementation of this tool. The proposed concept could become a support tool for company owners and managers to eliminating negative emotions and evoking positive emotions in employees during the process of implementation and enforcement of controlling into the enterprise, ensuring that this tool is fully functional and, accepted by all internal interest groups.
\end{abstract}

\section{Introduction}

Globalization impacts are now radically changing the economy and culture of individual countries. This new economy is becoming decisive in competition for a position in the global community of nations, as it presents enormous potential for economic growth, increased productivity, employment, and hence the well-being of people. Economically developed countries are characterized by the gradual dominance of services in the economy and the tertiarisation of material production, the internationalization of services, the emergence of new modern forms of production and consumption of services. People, information, technology and logistics are the main resources in the course of high quality services provided. It is important to adopt, use and develop a quality management approach based on international ISO 9000 standards for the success of service enterprises in global markets in order to develop a unified corporate management system in global markets [1]. Quality management systems (QMS) include the organizational structure, activities, programmes and actions designed to ensure that a product, process or service conforms to the objectives and the purposes for which it is to be used [2]. The process approach is one

*Corresponding author: jarmila.klementova@tuzvo.sk 
of building block in QMS, not only focusing on results, but also examining the reasons of different quality levels and introducing corrective actions based on their findings [3]. Implementation of quality management in enterprises is an important step towards increasing quality, improving internal and external processes and relations of the enterprise, and its faster establishment on the market during the period of globalization and internationalization [4-5]. In addition to quality management, it is advantageous to implement other management tools at the same time, which enables the enterprise to achieve greater stability and efficiency in the market in a shorter period. Corporate controlling is one of the supporting management tools.

As a management tool, corporate controlling is gradually expanding to all types and sizes of enterprises as a result of the globalization of businesses and supplier-customer relations. According to [6-7], recent mega trends changed the expectation of the management concerning the controlling function, meaning that controlling has to adapt to the new requirements. According to [8-9], controlling should be part of every modern enterprise, because its role is to prepare documents for managers who make optimal business decisions on their basis. Controlling is a fundamental part of fulfilling the business strategy and a way to change the view of, as well as the approach to, analyzing the status of the planned tasks. In implementing and using of controlling there is a need to take to take into account the psychological aspects affecting internal interest groups. Human resources represent a flexible component in view of performance and benefits for the enterprise and bring changes to the enterprises. For its successful implementation it is important to know the expectations and concerns of employees, managers and business owners. Controlling does not only act as a tool which supports planning, coordination and control of activities (external influence), but also acts as the internal process that affects the behaviour and actions of all people in the enterprise [10]. As [11] states, psychology makes it possible to understand the perception, thinking, emotions, learning, and the activation of processes. Therefore, it can be said that psychology becomes one of the most important components of controlling because they have a common object of influence. The subject of influence is a person whose business activity is purpose-built. As [12-13] point out, 6 rules apply in terms of psychology in workplace relationships between the controller, managers, and employees who are the recipients of the controller's information and recommendations, which must be accepted and applied in the enterprise with regard to the effectiveness of its implementation and enforcement within the enterprise. These include motivation, feedback, cooperation, building trust, enforcing, and change.

The decision to examine the psychological aspects of controlling and, quality management is based on this inseparable link. It is understood as a prerequisite for the implementation and streamlining of the functioning of individual management tools simultaneously and in mutual support.

\section{Methods}

The aim of the paper is to determine the key socio-economic factors affecting employees of service enterprises in the phase of implementation and enforcement of QMS and controlling in Slovak enterprises. The individual factors were compared for the above mentioned management tools in order to determine their structure and the impact on employees. The aim was to find out whether the socio-economic aspects are positive or negative and their match rate. Simultaneous implementation of two or more management tools would address and remove staff barriers and concerns, and to accelerate the process of implementation. The gradual implementation of tools is time-consuming and disadvantageous for enterprises due to possible loss of business relationships. It is recommended to implement several tools simultaneously. 
Based on the analysis of secondary sources of domestic and foreign authors, the issue was examined and the theoretical basis for solving the problem and the model design were created. In the second phase, an empirical survey was carried out on a sample of Slovak micro and small service enterprises. A questionnaire method was used to collect primary research data. There were processed 420 questionnaires were from enterprises in the framework of evaluation where the monitored tools are implemented, are in the process of implementation or are considering it and employees are informed about it. Of the total, 38\% were micro and $62 \%$ were small enterprises. Empirical survey data were evaluated by descriptive and graphical methods. In the third phase, positive and negative socio-economic factors were identified which are significant in the implementation of controlling and quality management for employees. Subsequently, a model was proposed for the implementation of management tools into practice for micro and small enterprises. The model depicts essential factors and relationships with an emphasis on employees. The aim is to facilitate the implementation of these tools to ensure their functionality after being implemented and full functionality after the barriers have been removed. This will increase the value of the enterprise on the market.

\section{Results and discussion}

The following section provides an analysis of the results of the influence of sociopsychological factors on employees of service enterprises in the implementation of new management tools. The results are processed graphically and descriptively for the area of controlling and quality management. There are listed basic socio-psychological factors (motivation, feedback, communication, change, enforcement, trust) separately for individual managerial tools. Figure 1 shows the impact of controlling implementation in enterprises. In motivation, $39 \%$ of respondents stated a large influence, $37 \%$ a very large influence, and $18 \%$ a small influence.

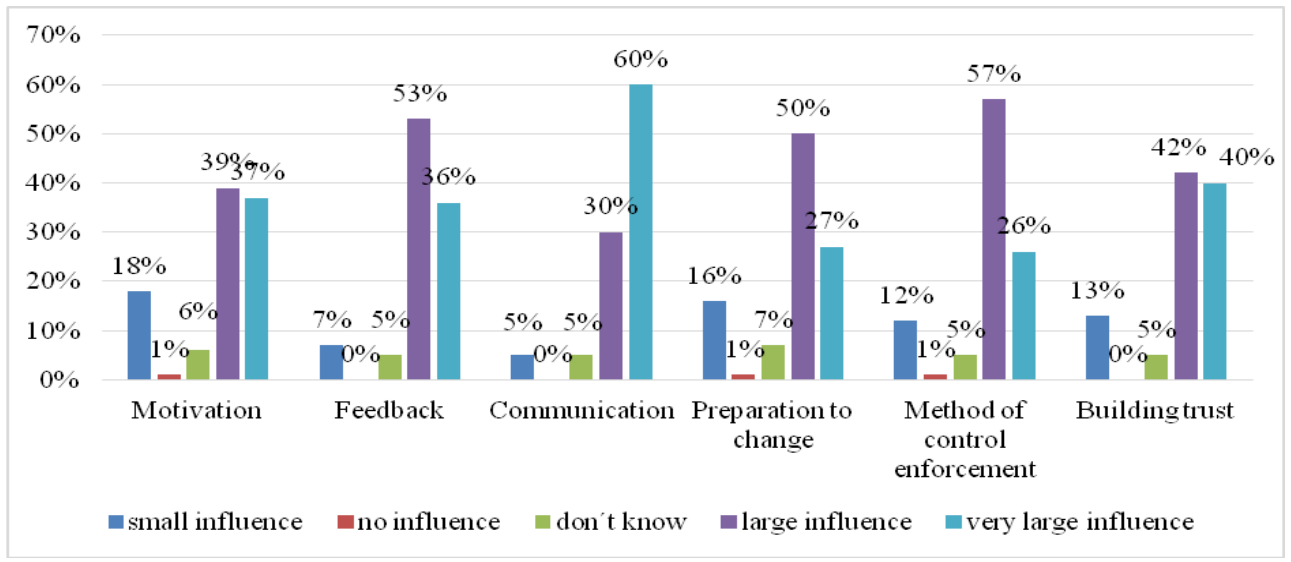

Fig.1. Influence of the controlling implementation on socio-psychological factors.

The second factor was feedback, $53 \%$ of respondents reported a large impact, $36 \%$ a very large impact, only 7\% a small impact. Communication is an important aspect for $60 \%$ of employees with very large influence, and $30 \%$ of employees with large influence. In connection with the implementation of controlling, up to $77 \%$ of employees expect major changes in the enterprise. Employees also expect significant influence in enforcing controlling $(83 \%)$. Trust recorded a large to very large impact $(82 \%)$. Almost none of the respondents expect that the implementation of controlling will not change anything. 
Figure 2 shows the influence of quality management implementation on sociopsychological factors in view of the employees' perceptions. It was confirmed that employees perceive the new management tool as a significant influence and change. In all factors, the highest values range with the possibility of a large and very large impact, with a sum total of $80 \%$ to $97 \%$ for feedback, which is closely related to communication. Its improvement can positively affect working conditions. The exact numerical values of opinions for each factor are shown in the figure 2.

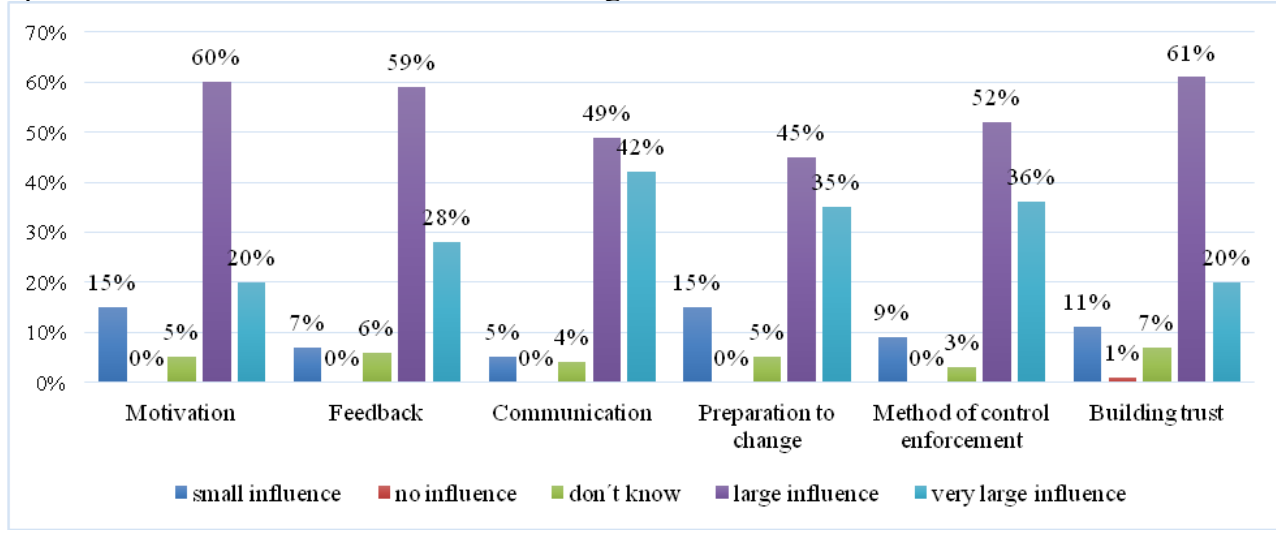

Fig. 2. Influence of the quality management implementation on socio-psychological factors.

It can be concluded that implementation of both instruments into the enterprises brings a significant impact on socio-psychological factors in view of employee perception.

There are presented opinions of employees on the economic benefits of the implementation of new management tools in the next section. The results of the research of opinions on the implementation of controlling and quality management are graphically processed in figure 3. The values of the individual benefits listed above range from $30 \%$ upwards. The lowest assumption of benefits is by the labour productivity growth $(34 \%$ and $30 \%$ ), by conformity of all types of plans with objectives (35\% and $36 \%$ ). Employees expect the highest benefits by the streamlining process quality, up to $68 \%$ for quality management and $42 \%$ for controlling. The quality management also achieves a significantly higher value by the deviations detection through measurable indicators. Employees assume that the quality management will pay more attention to these areas, which is also based on the nature of individual instruments. More than $50 \%$ of the benefits are achieved with both tools in improvement of processes performance with the effect on cost reduction and in controlling the achievement of business objectives at all levels.

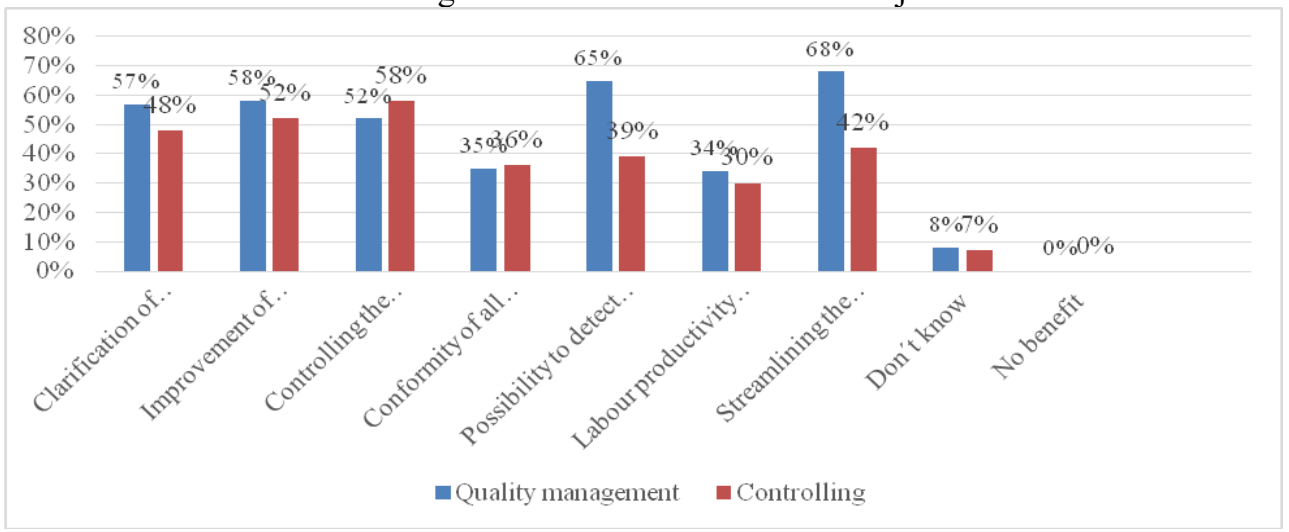

Fig. 3. Economic benefits of the quality management and controlling implementation. 
Considering that employees are familiar with the nature of individual management tools, it can be assumed that the assessment of economic benefits is based on this knowledge, as well as on the knowledge of their own business operations. Employee knowledge and awareness brings confidence and more concrete expectations into the enterprise, allowing employees to focus more on their work and improve performance. Lack of information brings uncertainty and concern, and creates barriers to implementing change. Figure 4 shows the values of individual employee barriers (concerns) in implementing quality management and controlling.

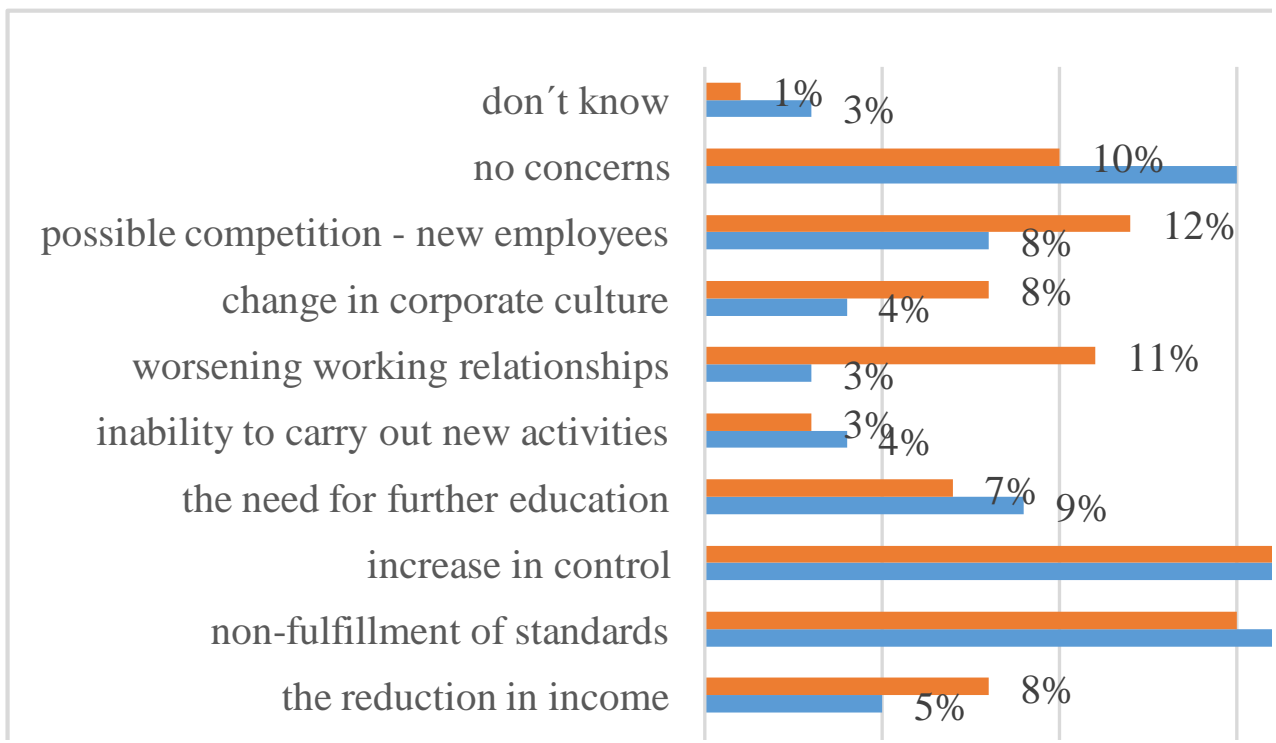

Fig. 4. The most significant barriers (concerns) of employees in implementing quality management and controlling.

Employees are most concerned about the increase in control in all areas, with $17 \%$ controlling and up to $10 \%$ more with the quality management. Employees are also concerned about excessive control, where $26 \%$ with the quality management are worried, and also worry about nonfulfillment of standards. Only $3 \%$ of employees are worried about the deterioration of relationships in the workplace, while controlling is up to $11 \%$. Similar differences in favour of the quality management are also in fear of change in corporate culture. Based on the results, it can be concluded that there were the biggest differences in the evaluation of barriers in individual management tools in all monitored factors.

It is important to monitor these factors and, to eliminate them gradually by adequate management methods and tools, and communication at all levels. Relevant information is essential in service enterprises where employees come into direct contact with customers. It is necessary that customers are informed about the changes and, if they are interested, so employees are able to respond to their questions. This creates trust and satisfaction not only in the contact employee but also in the enterprise itself. The fast and smooth implementation of management tools is important in terms of business relations and the position of the enterprise in global markets.

Based on primary and secondary sources, a model was proposed (figure 5) showing the influence of the key socio-economic factors on employee satisfaction, with an emphasis on contact employees, their position vis-à-vis other interest groups, and the infulence on external customer satisfaction. The model shows the most influential factors in the implementation of selected management tools. The left side shows the impact in the implementation of quality management, the right side in the controlling. There is a growing 
emphasis on the communication, which directly or indirectly affects the quality of services and the market position of the enterprise. Only satisfied employees can provide quality service and build good customer relationships. The model is dedicated to the internal environment of the enterprise, which is involved in creating quality - positive or negative influences, relationships, processes. The model also captures the impact of the external environment in the current era of globalization, which requires enterprises to implement these management tools. These are becoming a prerequisite in international markets when establishing business relationships and customer confidence.

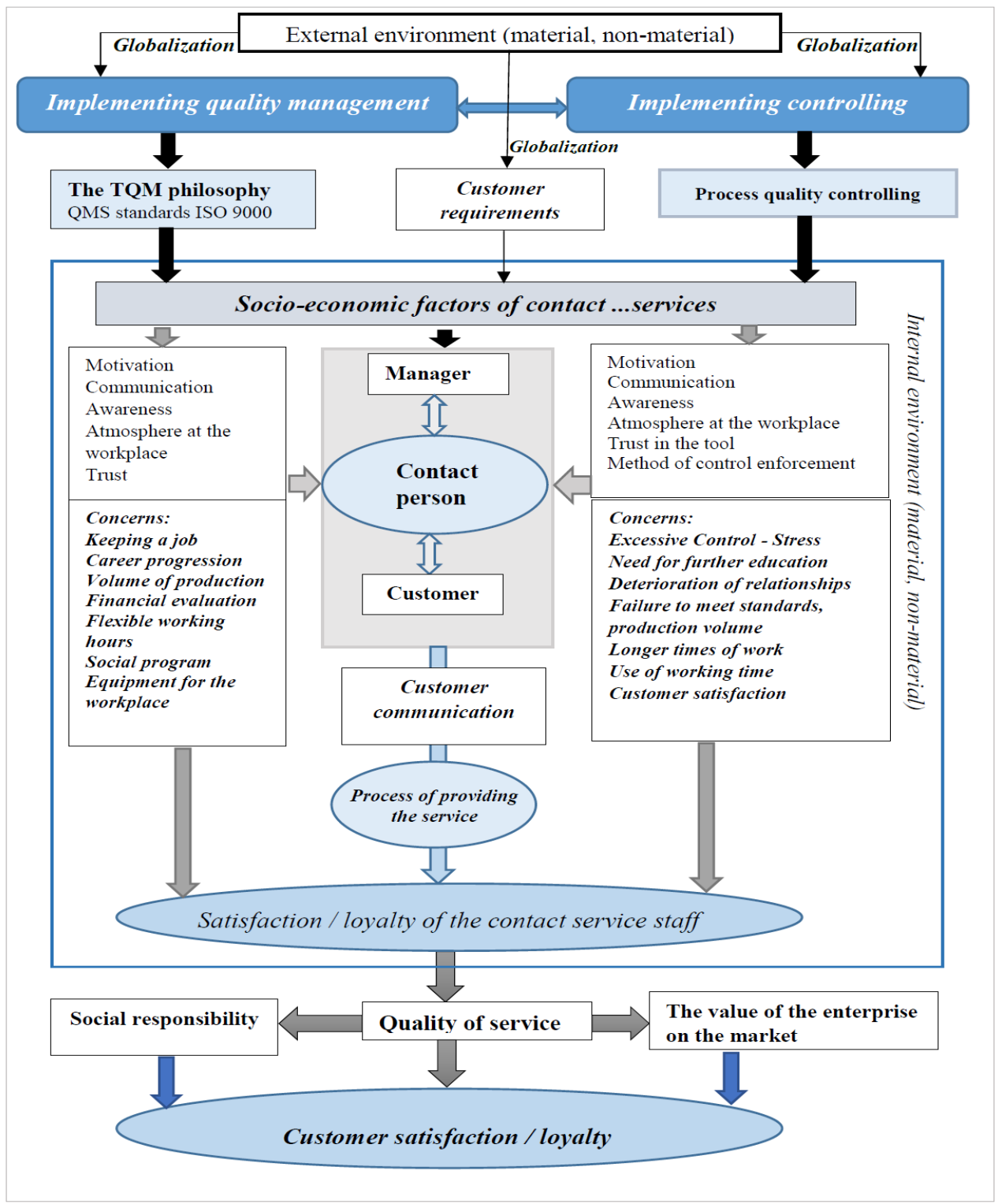

Fig. 5. Model of socio-economic factors of employees in implementing quality management and controlling. 


\section{Conclusion}

Global markets require the implementation of new management tools based on uniform international standards and rules. The success of a business and the introduction of change depend on people. The changes affect both managers and executives. It is important to choose the adequate approach so that it is acceptable to individual interest groups. Reconciling these interests in implementing changes depends on the personality of the managers. The effectiveness of specific management tools and the degree of their acceptance lies in seeking their positive and negative effects on employees. For executive or contact employees, the process of change in view of scope of work is usually simpler and more difficult in view of overcoming psychological barriers to change. According to [14], there is a need to look at the importance of employee and employer relations before considering major organizational changes and their implementation process. Communication is essential in finding and eliminating problems in the organization, but also in improving human relationships and developing teamwork [15-16]. Knowing and removing socio-economic barriers of employees is the basis for implementing new management tools and changes. These changes may be more sensitive and responsive in service enterprises, especially those types of services where the degree of contact between workers and customers is high. Satisfaction of contact staff is important. Good relationships within the organization are reflected in a positive approach to external customers. Quality in service enterprises is mainly distinguished by strategy and flexibility, with human resources playing an effective role in responding to changes in the current global environment [17-20].

This paper has been supported by funds of the projects VEGA No. 1/0010/17.

\section{References}

1. N. P. Solomon, A. Bester, C. M. Moll, Diffusion of a quality management system: a case study. South African Journal of Industrial Engineering 28, 2, 148-163 (2017)

2. F. Murmura, L. Bravi, Exploring customers' perceptions about quality management systems: an empirical study in Italy. Total Quality Management and Business Excellence 29, 11-12, 1466-1481 (2018)

3. H. Guo, R. Zhang, M. Zou, J. Yang, J. Zhang, Review on quality management model based on process approach. Business and Management Horizons 6, 2, 26-33 (2018)

4. S. Lukichev, M. Romanovich, The quality management system as a key factor for sustainable development of the construction companies. Procedia Engineering 165, 1717-1721 (2016)

5. G. Kutnjak, D. Miljenovic, A. Mirkovic, Improving competitiveness of small and medium-sized enterprises with the application of quality management system. Scientific Journal of Maritime Research 33, 11-21 (2019)

6. V. Laval, Improving the controlling function with a structured optimization project. Procedia Economics and Finance, 27, 54-63 (2015)

7. V. Laval, P. Stefea, The competitive challenge of controlling. Procedia - Social and Behavioral Sciences, 238, (2018)

8. Z. Chodasová, Podnikový controlling - nástroje manažmentu (2012)

9. T. Vuko, I. Ojvan, Controlling and business efficiency. Croatian Operational Research Review 4, 44-52 (2013)

10. T. Fischer, A. Sawczyn, The relationship between corporate social performance and corporate financial performance and the role of innovation: evidence from German 
listed firms. Metrika: International Journal for Theoretical and Applied Statistics 24, 1, 27-52 (2013)

11. P. Seeman, Psychológia v práci manažéra (2016)

12. R. Eschenbach, Controlling (2004)

13. M. Sedliačiková, Kontroling $v$ praxi podnikov v kontexte psychologických aspektov vnímania jeho prínosov a bariér internými záujmovými skupinami (2018)

14. M. N. Akhtar, L. Long, Organizational change determinants and employees behaviour: a psychological contract perspective. European Scientific Journal 11, 1, 189-199 (2015)

15. P. Král, V. Králová, Approaches to changing organizational structure: the effect of drivers and communication. Journal of Business Research 69, 11, 5169-5174 (2016)

16. R. Hasanaj, M. Manxhari, Importance of communication during change: a case of the municipality of Vlora. European Journal of Multidisciplinary Studies 2, 1, 15-19 (2017)

17. W. M. To, B. T. W. Yu, P. K. C. Lee, How quality management system components lead to improvement in service organizations: a system practitioner perspective. Administrative Sciences 8, 4, 73 (2018)

18. M. Uluskan, J. K. McCreery, L. Rothenberg, Impact of quality management practices on change readiness due to new quality implementations. International Journal of Lean Six Sigma 9, 3, 351-373 (2018)

19. F. Marimon, N. Melao, R. Bastida, Motivations and benefits of quality management systems in social services: mediation of the implementation process. Total Quality Management and Business Excellence, (2019)

20. T. F. Gonzalez-Cruz, N. Roig-Tierno, D. Bottela-Carrubi, Quality management as a driver of innovation in the service industry. Service Business 12, 3, 505-524 (2018) 